ENSV TEADUSTE AKADEEMIA TOIMETISED. XVI KOIDE

KEEMIA * GEOLOOGIA. 1967, Nr. 2

ИЗБЕСТИЯ АКАДЕМИИ НАУК ЭСТОНСКОИ ССР. ТОМ XVI

ХИМИЯ * ГЕОЛОГИЯ. 1967, № 2

О. ЭЙЗЕН, Ю. РИККЕН

\title{
О ХИМИЧЕСКОМ СОСТАВЕ ЖИДКИХ ПРОДУКТОВ, ОБРАЗУЮЩИХСЯ ПРИ НИЗКОТЕМПЕРАТУРНОМ ТЕРМИЧЕСКОМ РАЗЛОЖЕНИИ КЕРОГЕНА
}

Термическое разложение сланца изучалось многими исслелователями $\left.{ }^{[-8}\right]$. В настоящей работе приводятся некоторые новые данные об индивидуальном соста̀ве смол, образующихся при низкотемпературном $\left(270-350^{\circ} \mathrm{C}\right)$ термическом разложении сланца.

Новизна приводимых здесь данных заключается в основном в результатах количественного определения индивидуального состава смол. Данные об индивидуальном составе смол, полученных при низкотемпературном разложении сланцевого керогена, позволяют сделать некоторые выводы о его строении. Объясняется это тем, что продукты разложения, образовавшиеся в рассматриваемом температурном интервале, имеют более первичный характер. Значительно труднее сделать заключения о составе керогена на основе химического состава жидких продуктов, полученных в туннельных печах. Вторичные реакции первичных продуктов разложения здесь слишком сложны и трудно прослеживаются.

В опытах, проводимых при низких температурах, когда количество выделяющихся продуктов мало, желательно применять больше керогена, чтобы получить необходимое для анализа количество вещества. Равномерное нагревание большего количества керогена требует специально сконструированного аппарата, в котором толщина слоя керогена не превышала бы 6-8 мм. Тонкий слой керогена прогревается быстрее, и продукты разложения । извлекаются из реактора кратчайшим путем. Принимая во внимание эти соображения, установку сконструировали цилиндрической, поместив в нее 20 медных тарелок. Высота стенок тарелок достигала 10 ми. Через центр тарелок проходила 20-миллиметровая перфорированная трубка сборника для вывода продуктов полукоксования из слоя керогена, находившегося на тарелках. Для достижения лучшей теплопроводности тарелки плотно прилегали к стенке цилиндрического сосуда. Цилиндрический сосуд был снабжен нагревательной спиралью мощностью 1,2 кв.

Сланцевый кероген имел состав, приведенный в табл. 1.

Таблица 1

Характеристика керогена

\begin{tabular}{c|c|c|c|c|c|c|c}
\hline $\begin{array}{c}\text { Влаж- } \\
\text { ность, } \\
\%\end{array}$ & $\begin{array}{c}\text { 3ола, } \\
\%\end{array}$ & $\mathrm{CO}_{2}, \%$ & $\begin{array}{c}\text { Содержа- } \\
\text { ние орга- } \\
\text { нической } \\
\text { части, \% }\end{array}$ & \multicolumn{4}{|c}{ Элементарный состав, \% } \\
\hline 1,09 & 20,0 & - & 78,91 & 76,6 & C & S & $\mathrm{N}+\mathrm{O}+\mathrm{Cl}$ \\
\hline
\end{tabular}

Методика проведения опытов была следующей.

В опыте I определяли начальную температуру разложення керогена, за которую принимали появление первой капли смолы. Ниже $270^{\circ}$ разложения не происходило. 
Поэтому за температуру начала разложения приняли интервал $272-280^{\circ}$. Кероген выдерживали при указанной температуре до прекращения выделения смолы. Затем температуру повышали до $300^{\circ}$ и кероген выдерживали также до прекращения образования смолы. Последний этап протекал пири температуре $330-332^{\circ}$.

Опыт II проводили при $275^{\circ}$, так же, как и опыт I, но ограничиявались лишь указанной температурой и опыт проводили в течение более длительного времени.

В опыте III термическую обработку начинали сразу с температуры $300^{\circ}$, после прекращения выделения смолы переходили на температуру $330-340^{\circ}$. В конце опыта температуру повышали до $390^{\circ}$ и заканчивали опыт при $525^{\circ}$.

Опыт IV проводили при температуре $300^{\circ}$, как и опыт III. В этом опыте ограничились вышеуказанной температурой, но длился он дольше.

B опыте V проводили термическое разложение тяжелой смолы туннельных печей. Изучался химический состав образовавшихся продуктов разложения и результаты сравнивались с данными опытов I-IV. Тяжелая смола для опыта получалась путем отгонки более легкой части из суммарной смолы, кипящей до $275^{\circ}$ при остаточном давлении 1 мм рт. ст. Полученный остаток помещали на тарелки ранее описанного аппарата в виде пемзы, пропитанной вышеуказанной смолой.

Результаты опытов приведены в табл. 2.

Таблииа 2

Низкотемпературное разложение керогена и тяжелой сланцевой смолы

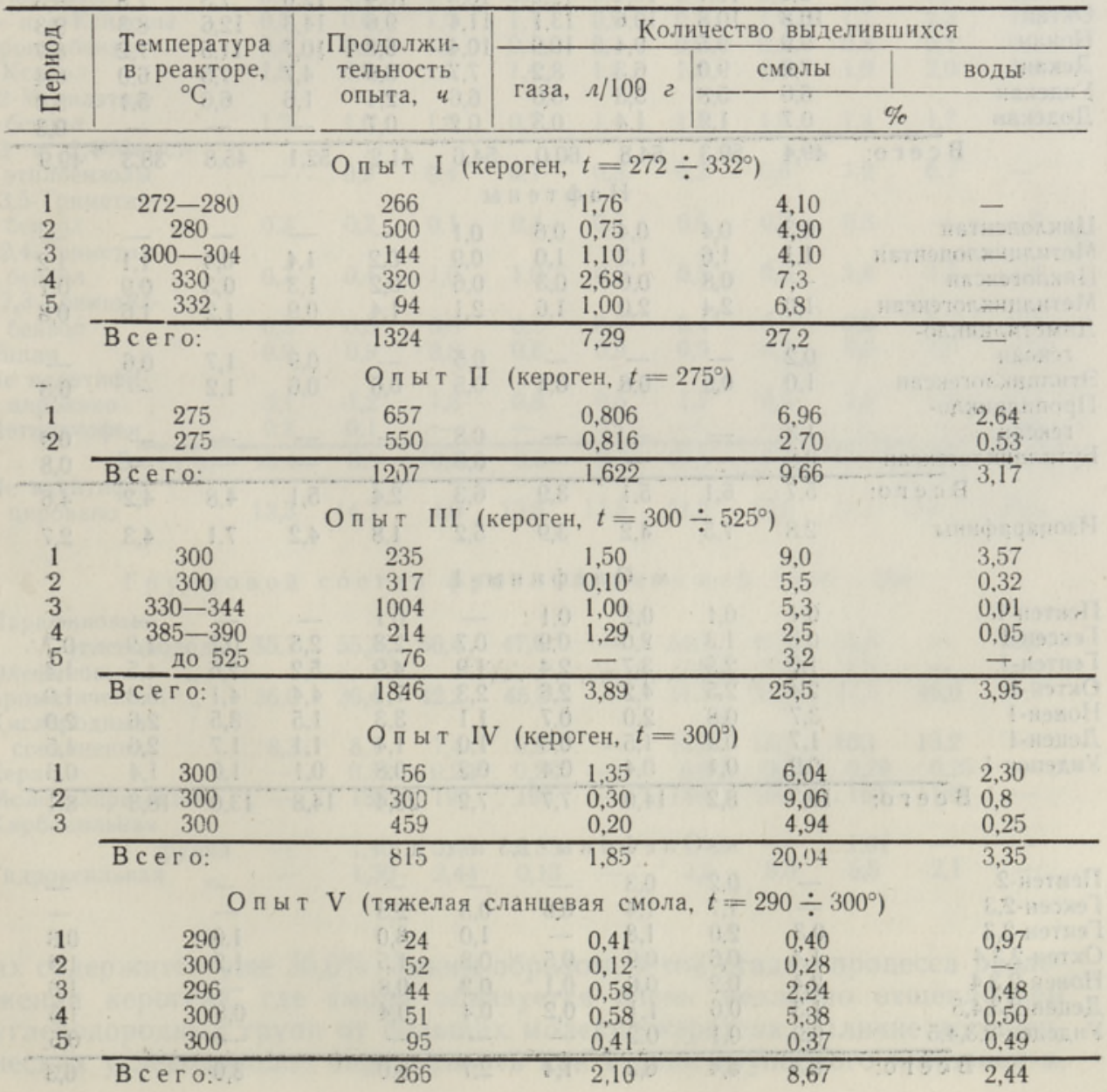


Результаты определения химического состава [9] смолы опыта I $(1+2)$, приведенные в табл. 3, показывают начало образования ароматических углеводородов при термическом разложении керогена сланца. Фракция бензина, полученная при $272-280^{\circ}$, содержит $10,4 \%$ ароматических углеводородов, в то время как в кипящей выше $200^{\circ}$ смоле

Таблица 3

Химическнй состав жидких продуктов (\%), полученных при разложении керогена

\begin{tabular}{|c|c|c|c|c|c|c|c|c|c|c|}
\hline \multirow{4}{*}{$\begin{array}{l}\text { Название } \\
\text { соединений }\end{array}$} & \multicolumn{4}{|c|}{ Опыт I } & $\begin{array}{c}\text { Опыт } \\
\text { II }\end{array}$ & \multicolumn{4}{|c|}{ Опыт III } & $\underset{\mathrm{V}}{\mathrm{Ondт}}$ \\
\hline & \multicolumn{10}{|c|}{ Периоды опыта } \\
\hline & $1+2$ & 3 & 4 & 5 & $1+2$ & 1 & 2 & 3 & 4 & $1 \div 5$ \\
\hline & $\begin{array}{c}272-\overline{-} \\
-280^{c}\end{array}$ & $300^{\circ}$ & $330^{\circ}$ & $330^{\circ}$ & $275^{\circ}$ & $300^{\circ}$ & $300^{\circ}$ & $\left|\begin{array}{c}330- \\
-344^{c}\end{array}\right|$ & $390^{\circ}$ & $300^{\circ}$ \\
\hline
\end{tabular}

Индивидуальный состав фракции, выкипающей до $200^{\circ}$ H-П а р а фин ы

Бутан

Пентан

Гексан

Гептан

Октан

Нонан

Декан

Ундекан

Цодекан

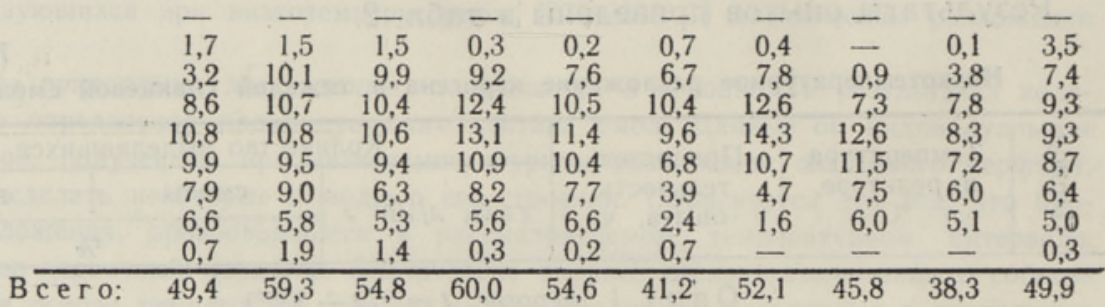

$\mathrm{H}$ а ф те н ы

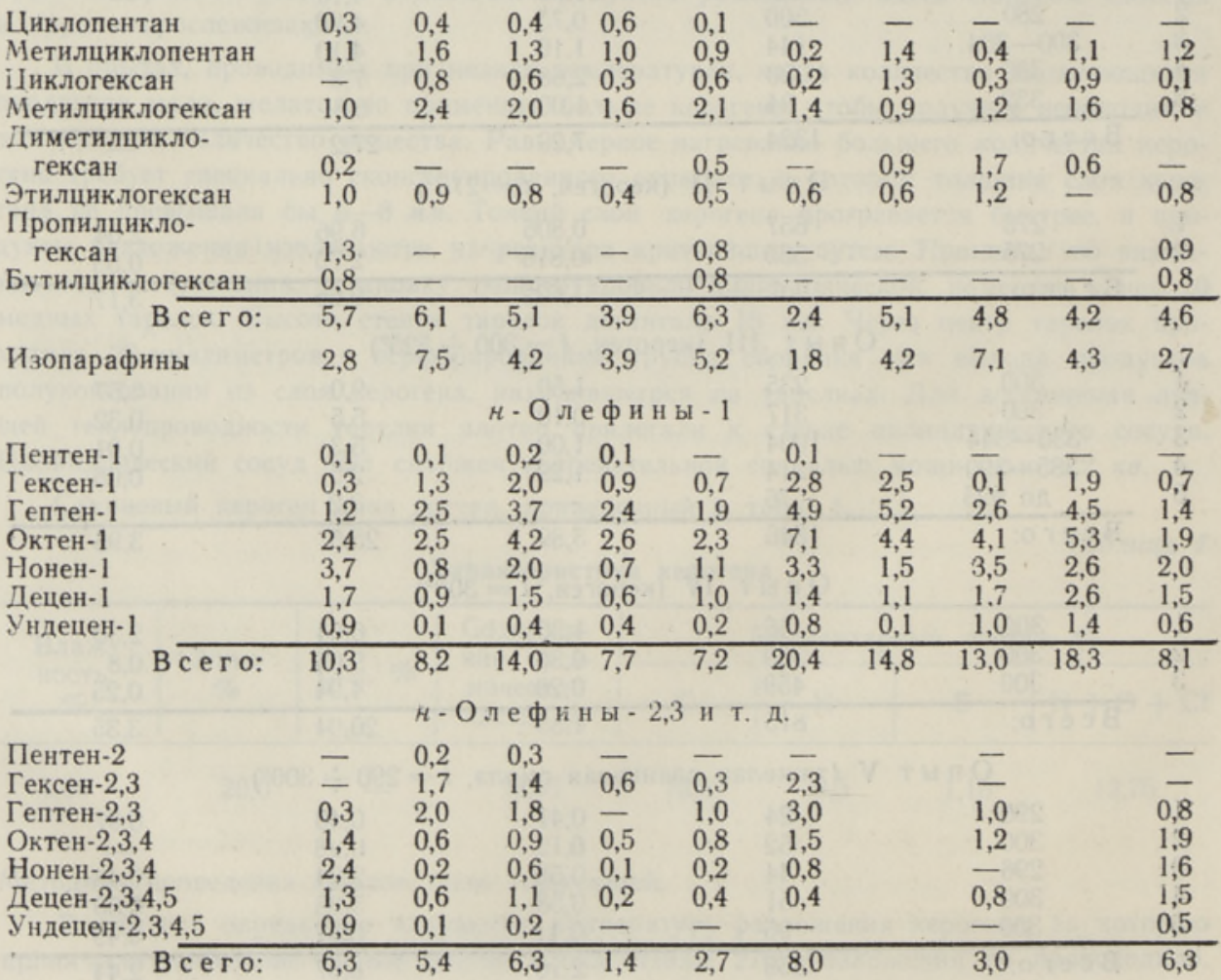


Продолжение табл. 3

\begin{tabular}{|c|c|c|c|c|c|c|c|c|c|c|}
\hline \multirow{4}{*}{$\begin{array}{l}\text { Название } \\
\text { соедннений }\end{array}$} & \multicolumn{4}{|c|}{ Опыт I } & \begin{tabular}{|c|} 
Oпыт \\
II
\end{tabular} & \multicolumn{4}{|c|}{ Опыт III } & $\begin{array}{c}\text { Oпыт } \\
\mathrm{V}\end{array}$ \\
\hline & \multicolumn{10}{|c|}{ Периоды опыта } \\
\hline & $1+2$ & 3 & 4 & 5 & $1+2$ & 1 & 2 & 3 & 4 & $1 \div 5$ \\
\hline & $\begin{array}{l}272- \\
-280^{\circ}\end{array}$ & $300^{\circ}$ & $330^{\circ}$ & $330^{\circ}$ & $275^{\circ}$ & $300^{\circ}$ & $300^{\circ}$ & $\begin{array}{l}330- \\
-344^{\circ}\end{array}$ & $390^{\circ}$ & $300^{\circ}$ \\
\hline
\end{tabular}

Циклоолефины

\begin{tabular}{|c|c|c|c|c|c|c|c|c|c|c|}
\hline Циклопентен & - & - & - & - & - & 0,5 & 0,6 & 一 & - & - \\
\hline Циклогексен & 0,4 & 0,3 & 0,5 & 0,3 & 1,1 & 1,7 & 0,6 & 0,5 & 0,4 & 0,2 \\
\hline Метилциклогексен & 0,5 & 0,6 & 0,7 & 0,2 & 1,0 & 1,2 & 0,7 & 0,3 & 0,8 & 0,4 \\
\hline Этилциклогексен & 0,5 & 0,4 & - & 0,1 & 0,4 & 0,9 & 0,7 & 0,2 & 0,2 & 0,2 \\
\hline $\begin{array}{l}\text { Пропилцикло- } \\
\text { гексен }\end{array}$ & 0.2 & & & & & & & & & \\
\hline Бутилциклогексен & 0,2 & - & - & - & 0,16 & - & - & - & 一 & - \\
\hline Bсего & 1,8 & 1,3 & 1,2 & 0,6 & 3,06 & 4,3 & 2,6 & 1,4 & 1,4 & $\overline{0,8}$ \\
\hline
\end{tabular}

\begin{tabular}{|c|c|c|c|c|c|c|c|c|c|c|}
\hline Бензол & 0,1 & 0,1 & 0,1 & 0,2 & 0,1 & 0,1 & 0,1 & 0,1 & 4,3 & 0,2 \\
\hline Толуол & 0,4 & 0,7 & 0,9 & 1,0 & 0,9 & 1,2 & 0,9 & 1,1 & 1,6 & 0,5 \\
\hline Этилбензол & 0,4 & 0,6 & 0,6 & 0,5 & 0,6 & 0,7 & 0,7 & 0,6 & 1,1 & $0, \overline{5}$ \\
\hline м- и n-Ксилолы & 0,5 & 0,6 & 1,0 & 1,1 & 0,9 & 0,8 & 1,0 & 1,7 & 2,3 & 1,0 \\
\hline Пропилбензол & 0,4 & 0,2 & 0,2 & 0,1 & 0,3 & 0,9 & 0,3 & 0,3 & 0,1 & 0,3 \\
\hline о-Ксилол & 1,9 & 0,9 & 1,6 & 1,4 & 1,5 & 1,5 & 1,3 & 1,9 & 2,0 & 1,9 \\
\hline $\begin{array}{l}\text { 1,2-Метилэтил- } \\
\text { бензол }\end{array}$ & 1,2 & 1.0 & 1,0 & 0,7 & 1.4 & 1,3 & 1.0 & 1.4 & 1,7 & 1.7 \\
\hline 1,3 и 1,4-Метил- & & & & & & & & & & \\
\hline $\begin{array}{l}\text { Этилбензолы } \\
\text { 1,3,5-Триметил- }\end{array}$ & - & 0,9 & 0,4 & 0,7 & 0,8 & 0,2 & 0,6 & 1,2 & 0,7 & - \\
\hline $\begin{array}{l}\text { бензол } \\
\text { - } 4 \text {-Т }\end{array}$ & 0,3 & 0,2 & 0,1 & 0,1 & 0,3 & 0,6 & 0,2 & 0,3 & - & 0,3 \\
\hline $\begin{array}{l}\text { бензол } \\
1,2,3-\text { Триметил- }\end{array}$ & 0,7 & 0,4 & 1,0 & 1,0 & 0,5 & 0,5 & 0,9 & 1,4 & 1,1 & 1,4 \\
\hline бензол & 0,3 & 0,5 & 0,8 & 0,2 & 0,5 & 0,4 & 0,3 & 0,9 & 0,7 & 0,9 \\
\hline Индан & 0,9 & 0,9 & 0,8 & 0,8 & 0,9 & 0,9 & 0,7 & 0,6 & 1,0 & 0,9 \\
\hline $\begin{array}{l}\text { Не идентифи- } \\
\text { цировано }\end{array}$ & 3,1 & 1,2 & 1,8 & 0,8 & 0,5 & 1,7 & 0,5 & 2,2 & 1,9 & 4 \\
\hline Метнлтиофен & 0,2 & 0,1 & & & 0,1 & - & 二 & $=$ & - & 0,1 \\
\hline $\begin{array}{l}\text { В се г о: } \\
\text { (1)нтифи- }\end{array}$ & 10,4 & 8,3 & 10,3 & 8,6 & 9,3 & 10,8 & 8,5 & 13,7 & 18,5 & 14,0 \\
\hline цировано & 13,3 & 14,7 & 4,0 & 13,6 & 11,5 & 11,2 & 12,6 & 11,1 & 15,1 & 6 \\
\hline
\end{tabular}

Групповой состав фракцин, кипящей выше $200^{\circ}$

Парафиновые $\begin{array}{lllllllll}\text { углеводороды } & 55,7 & 55,3 & 50,4 & 47,6 & - & 34,5 & 47,4 & 51,5\end{array}-53,5$

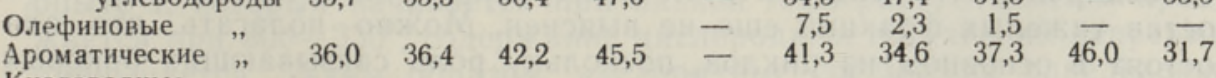
$\begin{array}{lllllllll}\text { Кнслородные " } & 8,3 & 8,3 & 7,4 & 6,9 & 16,7 & 15,7 & 10,1 & 13,2\end{array}$ $\begin{array}{lllllllllll}\text { соединения } & 8,3 & 8,3 & 7,4 & 6,9 & - & 16,7 & 15,7 & 10,1 & 13,2 & \text { - } \\ \text { Сера } & - & 0,32 & 0,29 & 0,27 & - & 0,85 & 0,32 & 0,29 & 0,25 & \text { - }\end{array}$ $\begin{array}{llllllllll}\text { Молекулярный вес } & - & 189 & 193 & 193 & - & 180 & 180 & 182 & 189\end{array}$ Карбонильная

Гидроксильна

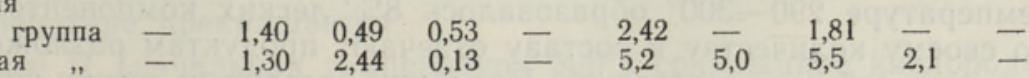

их содержится уже $36,0 \%$. Таким образом, в той стадии процесса разложения керогена, где смола образуется очень медленно отщеплением углеводородных групп от больших молекул керогена, наличие ароматических углеводородов определялось как в виде группового компонента, 
так и индивидуально. При анализе тяжелой части смолы был идентифицирован нафталин._Следовательно, как одноядерные, так и многоядерные ароматические соединения образуются при вышеназванных температурах одновременно, когда не происходит заметных вторичных изменений в отщепляющемся от керогена материале.

Для выделившихся из сланцевого керогена ароматических углеводородов наиболее характерно положение алкильных групп 1,2 или $1,2,4$. Положения 1,$3 ; 1,3,5$ и 1, 2, 3 встречаются значительно реже. Исходя из этого, можно полагать, что ароматические ядра в сланцевом керогене связаны с алифатическими радикалами преимущественно в положении 1,2 . Одно ядро связано двумя, реже тремя боковыми цепями с молекулой керогена. Четыре алкильных цепи у бензольного кольца встречаются очень редко. Кажущееся малое число ядер с тремя и четырьмя алкильными цепями в молекуле керогена, возможно, обусловлено также тем, что при наличии нескольких цепей некоторые из них не рвутся, вследствие чего ароматическое ядро не отделяется от молекулы керогена.

O неароматических циклах, присутствующих в керогене, можно сказать следующее.

В керогене должны отсутствовать циклоолефиновые группировки. Поскольку, однако, они содержатся в небольшом количестве в смоле, полученной при $272-280^{\circ}$, то можно предположить, что они образовались в процессе разложения. Содержание нафтеновых соединений в той же смоле в $3-5$ раз выше содержания циклоолефиновых, что указывает на присутствие циклопарафинов уже в керогене. Из расчетных данных следует, что нафтеновые и ароматические циклы появляются в сланцевом керогене в соотношении $1: 1$. Такоє соотношение циклов характерно лишь для части керогена, разлагающейся при 270-280 . Неразложившаяся часть более циклична и термически устойчива. Заслуживает внимания тот факт, что соединения с нормальными цепями в смоле промышленных установок полукоксования присутствуют главным образом лишь в части, кипящей ниже $250^{\circ}$. Во фракциях, кипящих выше $300^{\circ}$, их содержание быстро падает. Согласно данным табл. 3, максимальное количество нормальных углеводородов, выделенных из керогена, приходится на долю $\mathrm{C}_{7}-\mathrm{C}_{9}$. Можно полагать, что циклы керогена объединяются цепями, состоящими главным образом из углеродных атомов от 6 до 11. Это заключение справедливо при условии, что цепи рвутся вблизи ядер.

Из состава сланцевой смолы следует, что в процессе термического разложения керогена образуются нормальные, с различной длиной боковой цепи, ароматические, циклопарафиновые и циклоолефиновые углеводороды и тяжелый остаток кислородных соединений. Химический состав тяжелых фракций еще не выяснен. Можно полагать, что они состоят в основном из циклов, поскольку роль связывающих боковых цепей мала. Следует отметить, что тяжелая смола разлагается дальше главным образом в соответствии с теми же закономерностями, что и кероген. Из тяжелой смолы до полного прекращения разложения при температуре $290-300^{\circ}$ образовалось $8 \%$ легких компонентов, которые по своему количеству и составу отвечают продуктам разложения керогена при той же температуре. Половину указанных легких компонентов, т. е. $4 \%$, составляют $н$-парафиновые углеводороды. С учетом содержания олефиновых углеводородов продукты, образовавшиеся при термическом разложении тяжелой смолы, содержат до $65 \%$ соединений с неразветвленной цепью. Вероятно, межциклический основной запас цепей тем самым исчерпан и поэтому разложение при данной температуре 
прекращается. Разрушение циклов требует, очевидно, более высокой температуры.

Таким образом, при быстром нагревании сланца (например, в туннельных печах) образуется ряд углеводородов и кислородных соединений с различным молекулярным весом, имеющих главным образом нормальные цепи и составляющих основную часть сланцевого бензина. Вследствие разрушения цепей в керогене освобождаются различные циклические соединения, которые дают циклическую часть бензина. При быстром разложении керогена в туннельных печах реакции термического разложения не успевают достигнуть состояния равновесия. Этим объясняется и то, что низкотемпературное разложение тяжелой сланцевой смолы протекает аналогично разложению керогена.

Основную часть $(2 / 3)$ промышленного сланцевого бензина составляют нормальные парафиновые и олефиновые углеводороды. Выше мы уже рассмотрели причины их образования. Бензин, полученный при температуре $272-280^{\circ}$, также содержит $66 \%$ соединений с нормальной цепью, а полученный при $300^{\circ}-70 \%$ и при $330^{\circ}-75 \%$ [см. табл. 3, опыт I $(1+2$ и $3+4)$ и опыт III (1 и 2)]. На первой стадии разложения содержание соединений с нормальной цепью даже меньше, чем при углублении разложения при данной или более высокой температуре. Отсюда следует, что: а) на первой стадии разложения выделяется больше циклических соединений, а это указывает на более слабую связь одних циклов с молекулой керогена по сравнению с другими; б) поскольку отношение циклических и нормальных алифатических соединений в промышленном агрегате и при низкотемпературном изотермическом разложении остается постоянным, эта особенность состава смол обусловлена свойствами керогена. От молекулы керогена отделяются длинные цепи. Часть их остается при разложении связанной с циклами (например, в смоле найдены $\boldsymbol{H}$-пентилбензол, $\boldsymbol{H}$-гексилбензол, $\boldsymbol{H}$-пентилциклопентен и т. д.), часть же образует нормальные углеводороды и кислородные соединения.

Как углеводородная часть, образующаяся при термическом разложении керогена, так и кислородные соединения состоят из соединений с нормальной цепью и циклических структур. Из циклических кислородных соединений важнейшими являются фенолы. Кислородные соединения с нормальной цепью состоят из кетонов и карбоновых кислот. Содержание кислородных соединений, образовавшихся в низкотемпературных опытах разложения керогена, относительно низкое. Отчасти это, очевидно, объясняется более высокими температурами кипения кислородных соединений. Рассматривая образование кислородных соединений в связи с режимом термической обработки, можно видеть, что в опыте I, который начинается при низкой температуре и затем продолжается при $300-330^{\circ}$, содержание кислородных соединений непрерывно уменьшается. Таким образом, кислородные соединения определенного вида выделяются уже при низкой температуре, среди них присутствуют соединения как с гидроксильной, так и с карбонильной группой; после того как эти структурные образования выделятся, разложение при данной температуре прекращается.

В опыте II (начальная температура $300^{\circ}$ ) содержание кислородных соединений в тяжелых фракциях в два раза выше, чем в опыте I. Отсюда следует, что:

а). в условиях продолжительной термической обработки характер кислородных групп в керогене изменяется и образуются газообразные продукты $\left(\mathrm{H}_{2} \mathrm{O}, \mathrm{CO}_{2}, \mathrm{CO}\right)$; выход жидких продуктов уменьшается вследствие внутримолекулярной перегруппировки; 
б) существуют стабильные кислородные группы, которые в процессе разложения керогена остаются в продуктах разложения с большим молекулярным весом; этим и обусловлено высокое содержание кислорода в тяжелых фракциях сланцевой смолы.

Сернистые соединения при низкотемпературном полукоксовании образуются наиболее интенсивно в первый период. Так, смола, образовавшаяся в первый период опыта III, содержит $0,85 \%$ серы, смола же, образовавшаяся позднее, но при этой же температуре, - 0,32\%. Термическая обработка, законченная при более высокой температуре $\left(390^{\circ}\right)$, еще более уменьшает содержание серы.

В процессе термического разложения керогена выделяются газ и жндкие продукты. В ранее опубликованных работах приводятся многочисленные данные о количестве и составе газовых продуктов, образующихся при термическом разложении сланца. В настоящей работе мы приводим данные о газах, образующихся при низкотемпературной термической обработке сланца (табл. 4). В отношении состава углеводородной части эти данные полнее, чем опубликованные данные других авторов.

Таблица 4

Состав газов, образовавшихся при низкотемпературной термической обработке керогена сланца

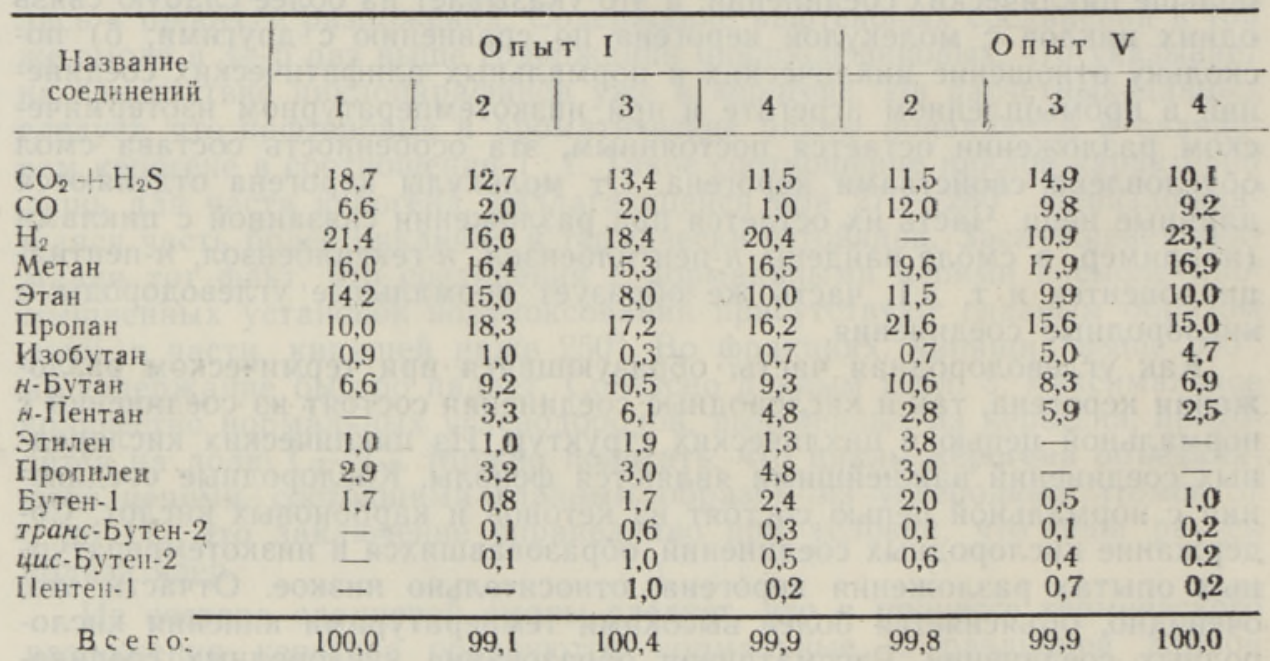

При низкотемпературном разложении из газообразных углеводородов выделяются в основном парафины и в значительно меньшем количестве - олефины. Это отвечает закономерностям состава жидких продуктов. Как в жндких, так и в газообразных продуктах изосоединений содержится мало.

Сравнение результатов газового анализа в опытах I и V показывает, что они в общем одинаковы. Это означает, что газообразные продукты, образовавшиеся при разложении керогена и сланцевой тяжелой смолы, одинаковы как по количеству, так и по составу. Газовые продукты опыта $\mathrm{V}$ содержат больше олефиновых углеводородов, чем продукты разложения керогена.

С учетом результатов газового анализа выясняется, что при термическом разложении сланцевого керогена одновременно образуются угле- 
водороды разного молекулярного веса, начиная от метана и кончая компонентами области тяжелых фракций смолы полукоксования. Многочнсленность различных группировок, образующихся при термическом разложении, обусловлена сложным строением молекулы керогена.

Авторы благодарят доктора химических наук А. С. Фомину за просмотр статьи и указания по ней.

\section{Л И ТЕ Р А Т У Р А}

1. А а рн а А. Я., Липпм а а Э. Г., Тр. Таллинск. политехн. ин-та. Сер. А, № 97, 3 (1958).

2. А а р н а А. Я., Тр. Таллинск. политехн. ин-та. Сер. А, № 57, 32 (1954).

3. А а рн а А. Я., Тр. Таллинск. политехн. ин-та. Сер. А, № 63, 65 (1965).

4. А а р а А. Я., Петухов Н. Ф., Тр. Таллинск. политехн. ин-та. Сер. А, № 73, 41 (1956).

5. К аск К. А., Тр. Таллинск. политехн. ин-та. Сер. А, № 73, 23 (1955).

6. Когерман П., Лутс К., Х юссе И., Химия эстонских сланцев, М.-Л., 1948.

7. М итюрев:А. К., Химия и технология горючнх сланцев и продуктов их переработки, Вып. 6, Л., 1958.

8. Ушаков С. Н., Иванов Б. И., Кирнллова С. И., Хим. пром., № 9,11 (1946).

9. Э й зен О., А р у ме ел Э., Изв. АН ЭССР. Сер. фнз.-матем. и техн. наук, 13, № 1 , 36 (1964).

Ннститут химии

Академии наук Эстонской ССР
Поступила в редакцию 21/IX 1966

\section{O. EISEN, J. RIKKEN}

\section{KEROGEENI MADALATEMPERATUURILISEL TERMILISEL LAGUNEMISEL TEKKIVATE VEDELATE PRODUKTIDE KEEMILISEST KOOSTISEST}

Uuriti kukersiidi kerogeeni termilist lagunemist temperatuuril $272-330^{\circ} \mathrm{C}$. Määrati vedelproduktide individuaalne ja grupiline koostis. Esitatakse mōningad seisukohad kerogeeni madalatemperatuurilise termilise lagunemise mehhanismi kohta.

\section{O. EISEN, J. RIKKEN}

\section{UBER DIE CHEMISCHE ZUSAMMENSETZUNG DER FLUSSIGEN SPALTPRODUKTE DER THERMISCHEN ZERSETZUNG DES KEROGENS BEI NIEDRIGEN TEMPERATUREN}

Es wird die Zusammensetzung von flüssigen Spaltprodukten des Kerogens bei der thermischen Zersetzung im Temperaturbereich von $272-330^{\circ} \mathrm{C}$ bestimmt. Hierbei werden einige Standpunkte über den Reaktionsmechanismus mitgeteilt. 